Article

\title{
Propane and Naphthalene Oxidation over Gold-Promoted Cobalt Catalysts Supported on Zirconia
}

\author{
María Silvia Leguizamón Aparicio ${ }^{1}$, María Lucia Ruiz ${ }^{2}$, Marco Antonio Ocsachoque ${ }^{1}$, \\ Marta Isabel Ponzi ${ }^{2}$, Enrique Rodríguez-Castellón ${ }^{3}$ and Ileana Daniela Lick ${ }^{1, *}$ \\ 1 CINDECA (CCT La Plata- CONICET-UNLP), Departamento de Química, Facultad de Ciencias Exactas, \\ Universidad Nacional de La Plata, Calle $47 \mathrm{~N}^{\circ}$ 257, La Plata, Buenos Aires 1900, Argentina; \\ mariasilvialap@quimica.unlp.edu.ar (M.S.L.A.); ocmarco@quimica.unlp.edu.ar (M.A.O.) \\ 2 INTEQUI (CCT San Luis- CONICET-UNSL), 25 de Mayo N 384, Villa Mercedes, San Luis, 5730, Argentina; \\ marialuciaruiz@yahoo.com.ar (M.L.R.); mponzi@unsl.edu.ar (M.I.P.) \\ 3 Departamento de Química Inorgánica, Cristalografía y Mineralogía, Facultad de Ciencias, Universidad de \\ Málaga, Campus de Teatinos, Málaga, 29071, Spain; castellon@uma.es \\ * Correspondence: ilick@quimica.unlp.edu.ar (I.D.L); Tel.: +54-221-4211353
}

Received: 5 March 2020; Accepted: 30 March 2020; Published: 2 April 2020

check for updates

\begin{abstract}
Zirconia-supported gold-promoted cobalt catalysts were synthesized and tested for the complete oxidation of propane and naphthalene. The catalysts were characterized by BET surface area, scanning electron microscopy (SEM), energy dispersive spectroscopy (EDS), powder X-ray diffraction (XRD), transmission electron microscopy (TEM), temperature-programmed reduction (TPR), and X-ray photoelectron spectroscopy (XPS). In both propane and naphthalene combustion reactions, the results obtained indicate that catalysts formulated with $\mathrm{Co}_{3} \mathrm{O}_{4}$ are more active than those containing only $\mathrm{Au}$. Catalysts prepared using the deposit/precipitation (DP) method have better activity than those in which the traditional technique is used. Gold addition using the DP methods generates a promoting effect on the activity of cobalt-containing catalysts. The AuDpCoZt catalyst was found to be the most active for both propane and naphthalene combustion. The catalytic behavior of this sample is associated with a synergic effect between gold, cobalt, and the support, which is also evidenced by an increase in the reducibility of this catalytic system. The effect of the presence of $\mathrm{NO}$ in the feed was also analyzed for propane combustion.
\end{abstract}

Keywords: gold; cobalt oxide; propane; naphthalene; catalytic oxidation

\section{Introduction}

Pollutants known as volatile organic compounds (VOCs) are emitted into the atmosphere from different sources. VOCs act as greenhouse gases, causing not only serious damage to the environment but also adverse health effects. A methodology used to reduce emissions from mobile sources is proposed by introducing catalytic converters to vehicle exhausts, where the oxidation of these gases to $\mathrm{CO}_{2}$ and $\mathrm{H}_{2} \mathrm{O}$ occurs at a low temperature. Catalytic oxidation is considered an efficient way to treat VOC emissions [1-4]. Systems based on supported noble metals (Pt, Pd, Au) are recognized among the most active catalysts for this process. The most widely studied catalysts are based on $\mathrm{Pt}$ and $\mathrm{Pd}$.

Since the 1980s when Haruta et al. [5,6] showed that Au nanoparticles supported on metal oxides present very high activities in $\mathrm{CO}$ oxidation, several research groups have been interested in the use of this metal for catalysis. For this reason, gold has been studied in many types of reactions [7-10] and has presented good activity, mainly in VOC oxidation [11-13]. Scirè and Liotta [14] described and critically analyzed the increasing use of gold catalysts in VOC catalytic oxidation. Among the extended VOC 
family, attention has been paid to the oxidation of saturated compounds (methane, ethane, propane, isobutene, $n$-hexane), unsaturated aliphatic compounds (acetylene, ethylene, propane), aromatic hydrocarbons (benzene, toluene, xylenes, naphthalene), alcohols (methanol, ethanol, isopropanol), aldehydes (formaldehyde), ketones (acetone), esters (ethyl acetate), etc. In addition, the reaction mechanism and influence of different factors, such as the nature and properties of the support, the size and shape of Au particles, the electronic state of gold, the preparation method, and the nature and concentration of organic molecules were discussed in detail. Nevertheless, the use of systems with gold for naphthalene catalytic combustion has rarely been reported in the literature.

On the other hand, much attention has been paid to non-noble metal oxide based catalysts for the abatement of various types of VOCs. Simple (e.g., $\mathrm{Co}_{3} \mathrm{O}_{4}, \mathrm{CuO}, \mathrm{NiO}, \mathrm{MnOx}, \mathrm{CeO}_{2}$, etc.) and mixed $\left(\mathrm{CuO}-\mathrm{ZrO}_{2}, \mathrm{ZrO}_{2}-\mathrm{CeO}_{2}, \mathrm{Co}_{3} \mathrm{O}_{4}-\mathrm{CeO}_{2}, \mathrm{MnOx}\right.$, etc.) oxides, perovskites, and spinels, among others, have been tested and showed high catalytic activity in this regard. Among them, $\mathrm{Co}_{3} \mathrm{O}_{4}$ is one of the most active [15,16], and many studies have been focused on the performance of this cobalt oxide spinel, in bulk form, with controlled crystallinity and porosity, or in supported phase form over a wide range of supports. The use of $\mathrm{Co}_{3} \mathrm{O}_{4}$-based catalysts offers the advantage of high activity and relatively low price compared to those based on noble metals.

The activity of oxidic catalysts can be promoted by the addition of small amounts of noble metals [17-20], for example, gold. Solsona et al. [17] studied the promoting effect of gold on the activity of some metal oxides (e.g., $\mathrm{CoOx}, \mathrm{MnOx}, \mathrm{CeO}_{2}$ ) in the total catalytic oxidation of methane, ethane, and propane, concluding that gold addition to metal oxides leads to an increase in catalytic activity. In this work, the $\mathrm{Au} / \mathrm{CoOx}$ catalyst was found to be the most effective. In addition, Ali et al. [18] observed that the addition of $\mathrm{Au}$ to a $\mathrm{MnOx} / \mathrm{TiO}_{2}-\mathrm{CeO}_{2}-\mathrm{ZrO}_{2}$ ) catalyst promotes activity due to an increase in the mobility of the lattice oxygen of the support. It has also has been reported that the addition of gold to $\mathrm{NiO}$ or $\mathrm{NiCeO}$ catalysts improves the redox properties of the system and, consequently, the catalytic activity [19].

The support has the role of controlling the amount of precious metals on the surface, the size and shape of the supported particles, as well as metallic dispersion. Zirconia $\left(\mathrm{ZrO}_{2}\right)$ is a widely-used support in catalysis because this oxide can present three crystalline structures: monoclinic, tetragonal, and cubic. The surface area, pore size, and acid-base characteristics of this support also strongly depend on the preparation conditions, thermal treatments, and interaction of the supported host ion with the oxidic matrix [21]. It is known that depending on the preparation method, a metastable tetragonal phase of $\mathrm{ZrO}_{2}$ can be obtained by thermal treatment at low temperatures. A procedure that allows obtaining metastable tetragonal zirconia is the addition of foreign ionic species to hydrous zirconia $\left(\mathrm{ZrO}_{2} \cdot \mathrm{nH}_{2} \mathrm{O}\right)$, also called zirconia hydrogel. Hydrous zirconia can be produced by drying hydrous zirconia sol synthesized by the hydrolysis of $\mathrm{ZrOCl}_{2}$ solutions [22].The ability of zirconia lattice to incorporate bivalent and trivalent cations generates deficient solid solutions with oxygen vacancies and crystalline networks that contain bulk and subsurface defects. Previous studies carried out by our research group showed that tetragonal phases can be generated by adding various cations of interest in catalysis (Co(II), $\mathrm{Cu}(\mathrm{II}), \mathrm{Ni}(\mathrm{II})$, or $\mathrm{Ag}(\mathrm{I}))$ to a zirconia hydrogel. In addition, the effect of the addition of cations and their oxides on the redox capacity of catalysts for hydrocarbon oxidation reactions was shown [23,24].

Some catalytic reactions have been found to be sensitive to monoclinic or tetragonal phase structure [25,26]. Oxidation reactions are favored when the migration of oxygen species from the bulk to the surface is facilitated and, for this purpose, the presence of oxygen vacancies is necessary. In this type of reaction, the role of $\mathrm{ZrO}_{2}$ is to be a source of lattice oxygen and it can also participate in the recovery of active sites by interaction of gas-phase oxygen with the support and supported oxide phases [18]. The activity of the supported phases depends on their interaction with the support, which can be modified during the catalyst preparation method. In this work, two gold and/or cobalt-containing catalyst series were prepared: the first one was obtained by impregnation of a commercial zirconia with a pre-established monoclinic structure and the other, from a hydrogel obtained in our laboratory 
by hydrolysis of $\mathrm{ZrOCl}_{2}$.In a previous work, it was reported that zirconia-supported cobalt oxide catalysts were active for the combustion of naphthalene [23].

The aim of the present work is to analyze the effect of gold addition on the physicochemical and catalytic properties of $\mathrm{Co}_{3} \mathrm{O}_{4}$-based catalysts supported on two types of zirconia (monoclinic and tetragonal zirconia, obtained from hydrated zirconium oxide). Moreover, gold addition was carried out by both a traditional impregnation and a deposit/precipitation (DP) technique. Both series of catalysts were tested in the catalytic combustion of two model molecules such as propane and naphthalene. It is worth mentioning that the $\mathrm{Au}-\mathrm{Co}_{3} \mathrm{O}_{4} / \mathrm{ZrO}_{2}$ system has not yet been used for propane and naphthalene elimination.

\section{Results and Discussion}

\subsection{Catalyst Characterizationm}

Table 1 shows the physicochemical properties of the catalysts and supports used in this work. Zirconia $(Z)$ is a commercial support with a pre-established monoclinic phase and a low surface area (8 $\mathrm{m}^{2} / \mathrm{g}$ ). On the other hand, the hydrous zirconium oxide prepared in our laboratory, $\mathrm{ZrO}_{2} \cdot \mathrm{nH}_{2} \mathrm{O}$, is a high surface area material $\left(340 \mathrm{~m}^{2} / \mathrm{g}\right)$. When this hydrated oxide is thermally treated as precursors are, at $600{ }^{\circ} \mathrm{C}$ for $2 \mathrm{~h}$, the loss of water and crystallization occur, and consequently the surface area decreases.

Table 1. Physicochemical properties of catalysts.

\begin{tabular}{cccccc}
\hline Catalyst & $\mathbf{S}_{\text {BET }}\left(\mathbf{m}^{2} / \mathbf{g}\right)$ & $\begin{array}{c}\text { Nominal } \\
\mathbf{C o} / \mathbf{Z}\end{array}$ & $\begin{array}{c}\text { EDS } \\
\mathbf{C o} / \mathbf{Z}\end{array}$ & $\begin{array}{c}\mathrm{Co}_{3} \mathbf{O}_{4} \text { Crystal } \\
\text { Size }(\mathbf{n m})\end{array}$ & $\begin{array}{c}\text { Au Particle } \\
\text { Size (nm) }\end{array}$ \\
\hline $\mathrm{ZrO}_{2}(\mathrm{Z})$ & 8 & - & - & - & - \\
$\mathrm{ZrO}_{2} . \mathrm{nH}_{2} \mathrm{O}$ & 340 & - & - & - & - \\
$(\mathrm{Zt})$ & 60 & - & - & - & - \\
$\mathrm{Zt} 600$ & 8 & - & - & - & 3.6 and $>30$ \\
$\mathrm{AuZ}$ & 58 & - & - & - & 1.9 and $>20$ \\
$\mathrm{AuZt}$ & 8 & - & - & - & 4.2 \\
$\mathrm{AuDpZ}$ & 60 & - & - & - & 3.1 \\
$\mathrm{AuDpZt}$ & 8 & 0.109 & 0.252 & 15 & - \\
$\mathrm{CoZ}$ & 37 & 0.109 & 0.240 & 22 & - \\
$\mathrm{CoZt}$ & 7 & - & - & 18 & 3.5 \\
$\mathrm{AuCoZ}$ & 8 & 0.109 & 0.067 & 18 & 4.3 \\
$\mathrm{AuDpCoZ}$ & 35 & - & - & 19 & 2.1 \\
$\mathrm{AuCoZt}$ & 34 & 0.109 & 0.103 & 17 & 3.2 \\
$\mathrm{AuDpCoZt}$ & & & & & \\
\hline
\end{tabular}

The addition of gold and cobalt phases does not generate any changes in the BET surface area of the commercial support (Z). Cobalt addition to the hydrogel and the subsequent thermal treatment cause an important and expected surface area loss even greater than that observed in the support without impregnation (Zt 600). Conversely, catalysts containing gold and cobalt present specific surface areas similar to those observed in supported cobalt catalysts. These results suggest that gold addition has not modified the catalyst textural properties.

Scanning electron microscopy- energy dispersive spectroscopy (SEM-EDS) tests were carried out with the purpose of obtaining a semi-quantitative analysis of cobalt content; the calculated $\mathrm{Co} / \mathrm{Z}$ ratios are listed in Table 1.Gold element concentration could not be evaluated since the emission lines overlap with those of zirconium element. The results obtained (Table 1) indicate that gold addition using the deposit-precipitation technique causes a decrease in cobalt concentration. The atomic content of surface cobalt is 3.78 times greater in the $\mathrm{CoZ}$ catalyst than in the AuDpCoZ catalyst. These results could indicate that gold species have been deposited on oxidic cobalt species. 
Figure 1 exhibits energy dispersive spectroscopy elemental mapping images showing the distribution of cobalt in AuDpCoZ and AuDpCoZt catalysts. The shining points, corresponding to cobalt, are homogeneously dispersed.

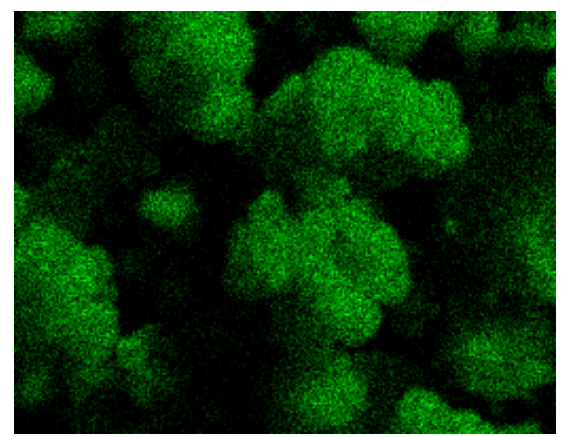

(A)

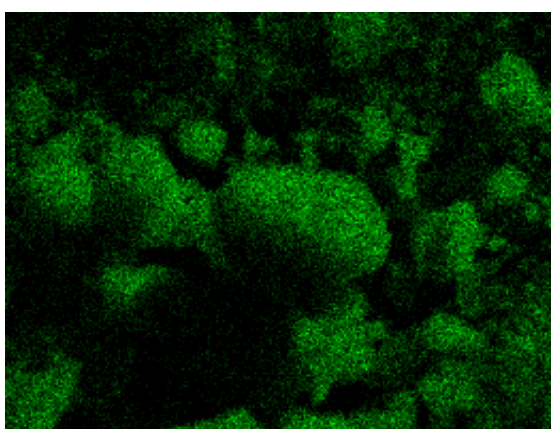

(B)

Figure 1. Energy dispersive spectroscopy (SEM-EDS) mapping image of Co in catalysts(A) AuDpCoZ and (B)AuDpCoZt.

Powder X-ray diffraction (XRD) analyses were performed to identify the crystalline phases of both the support and the supported species. Figure 2 shows the XRD patterns of CoZ, AuZ, AuCoZ, $\mathrm{AuDpZ}$, and $\mathrm{AuDpCoZ}$ catalysts with diffraction lines corresponding to monoclinic phase (M) of zirconia located at $2 \theta=28.2,31.5,34.2$, and $50.2^{\circ}$ (PDF No. 03-065-1025). This result is expected, given that the commercial zirconia used has a pre-established crystalline structure.

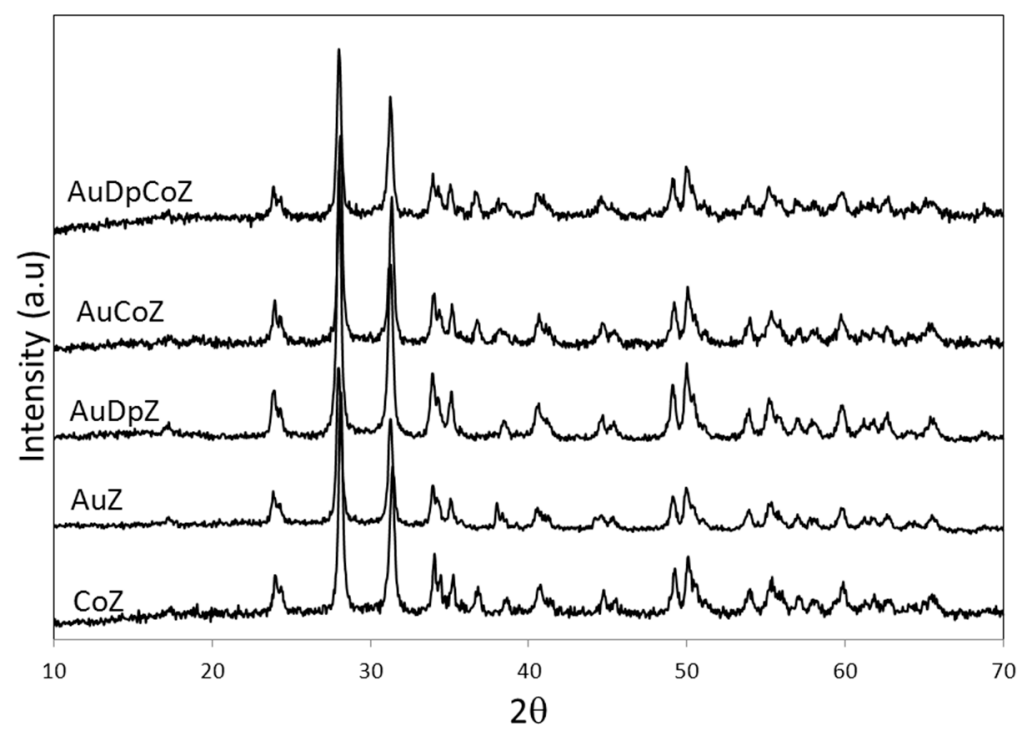

Figure 2. X -ray diffraction patterns of catalysts supported on monoclinic zirconia (Z).

In the case of CoZt, AuZt, AuDpZt, AuCoZt, and AuDpCoZt catalysts, which were prepared from zirconia hydrogel, the diffraction lines located at $2 \theta=30.0,35.0,50.0$, and $60.0^{\circ}$ (PDF No. 01-089-7710) correspond to tetragonal metastable phase $(\mathrm{T}$ ) of zirconia (Figure 3). Evidently, in most samples, there is some interaction between doping species and the zirconia hydrogel, generating the metastable tetragonal phase $[27,28]$ during the calcination process. The different behavior presented by the AuZt catalyst is worth noting. Its XRD pattern shows diffraction lines of two different crystalline phases of zirconia, i.e., monoclinic and tetragonal, the first being the most intense. This result suggests that the interaction between gold and the hydrogel is not favored when this metal is added using the traditional method. 


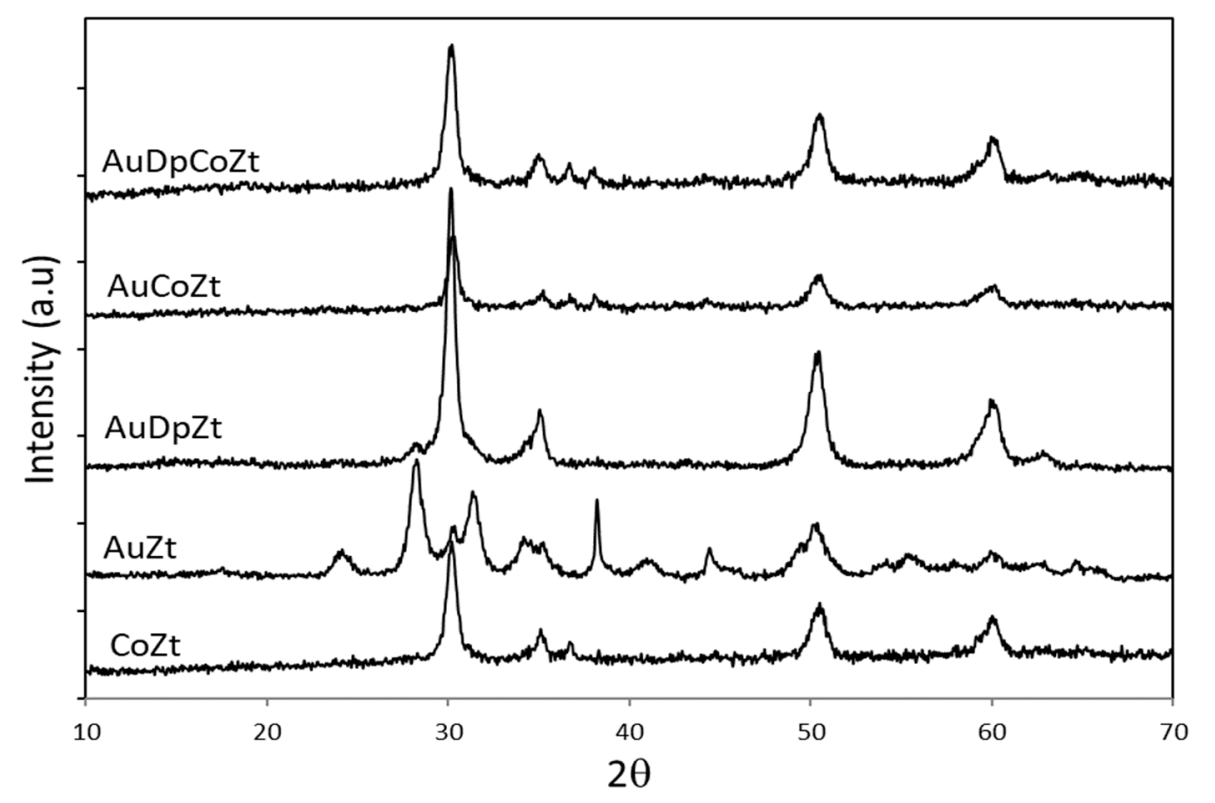

Figure 3. XRD patterns of catalysts supported on $\mathrm{Zt}$ zirconia.

Subsequently, the crystalline species generated by the supported phases were analyzed. The diffraction patterns of AuZ and AuZt catalysts, where gold was incorporated with the traditional technique, present diffraction lines corresponding to metallic gold species $2 \theta=38.3,44.5^{\circ}$ (PDF No.00-004-0784). These signals are more intense in the AuZt diffraction pattern. It is evident that gold, which is added as $\mathrm{HAuCl}_{4}$, is then reduced in the thermal treatment of precursors. Besides, $\mathrm{Au}^{0}$ lines are not clearly observed in the diffraction patterns of samples prepared with the DP method. It is evident that the gold addition method conditions both the formation of the support structure and the size of supported crystalline phases.

The XRD patterns of cobalt catalysts promoted with gold (AuCoZ, AuCoZt, AuDpCoZ, AuDpCoZt) do not clearly exhibit signals associated with the presence of metallic gold.

The presence of $\mathrm{Co}_{3} \mathrm{O}_{4}$ is evidenced in all cobalt-containing catalysts with characteristic diffraction lines located at $2 \theta=31.2,36.8,59.3$, and $65.1^{\circ}$ (PDF No. 01-080-1533).In order to see whether gold addition modifies the characteristics of cobalt spinel crystals, $\mathrm{Co}_{3} \mathrm{O}_{4}$, the crystal size was analyzed with the Scherrer equation from the diffraction line located at $2 \theta=36.8^{\circ}$, and the results obtained are reported in Table 1. All catalysts exhibit similar cobalt oxide crystal size, between 15 and $22 \mathrm{~nm}$. The addition of gold produces slight changes in the supported cobalt oxide crystal size. The addition of gold to CoZ catalysts, using both the traditional and the DP methods, led to a slight increase in the $\mathrm{Co}_{3} \mathrm{O}_{4}$ crystal size. Instead, the addition of gold to CoZt catalyst led to a slight decrease in the $\mathrm{Co}_{3} \mathrm{O}_{4}$ crystal size. These results evidence an interaction between gold and cobalt species.

In order to examine whether gold was in a metallic state, $\mathrm{Au}^{0}$, transmission electron microscopy (TEM) analyses were performed. TEM micrographs (see Supplementary Material Figure S1) revealed the presence of metallic particles in all gold-containing catalysts. The size distribution of gold particles for each sample was obtained from the micrographs; the histograms are shown in Figure 4 and the average values are listed in Table 1.Gold-containing catalysts obtained by the DP method and/or those containing cobalt exhibit a relatively narrow gold particle size distribution, mainly consisting of particles having diameters between 2 and $6 \mathrm{~nm}$, except for AuZ and AuZt catalysts, which exhibit a bimodal distribution of crystal size, crystals of a small size, and some crystals of a large particle size $(>20 \mathrm{~nm})$. The latter results are consistent with those obtained by XRD. It is evident that both the gold addition method and the presence of cobalt species influence the size distribution of gold particles. 

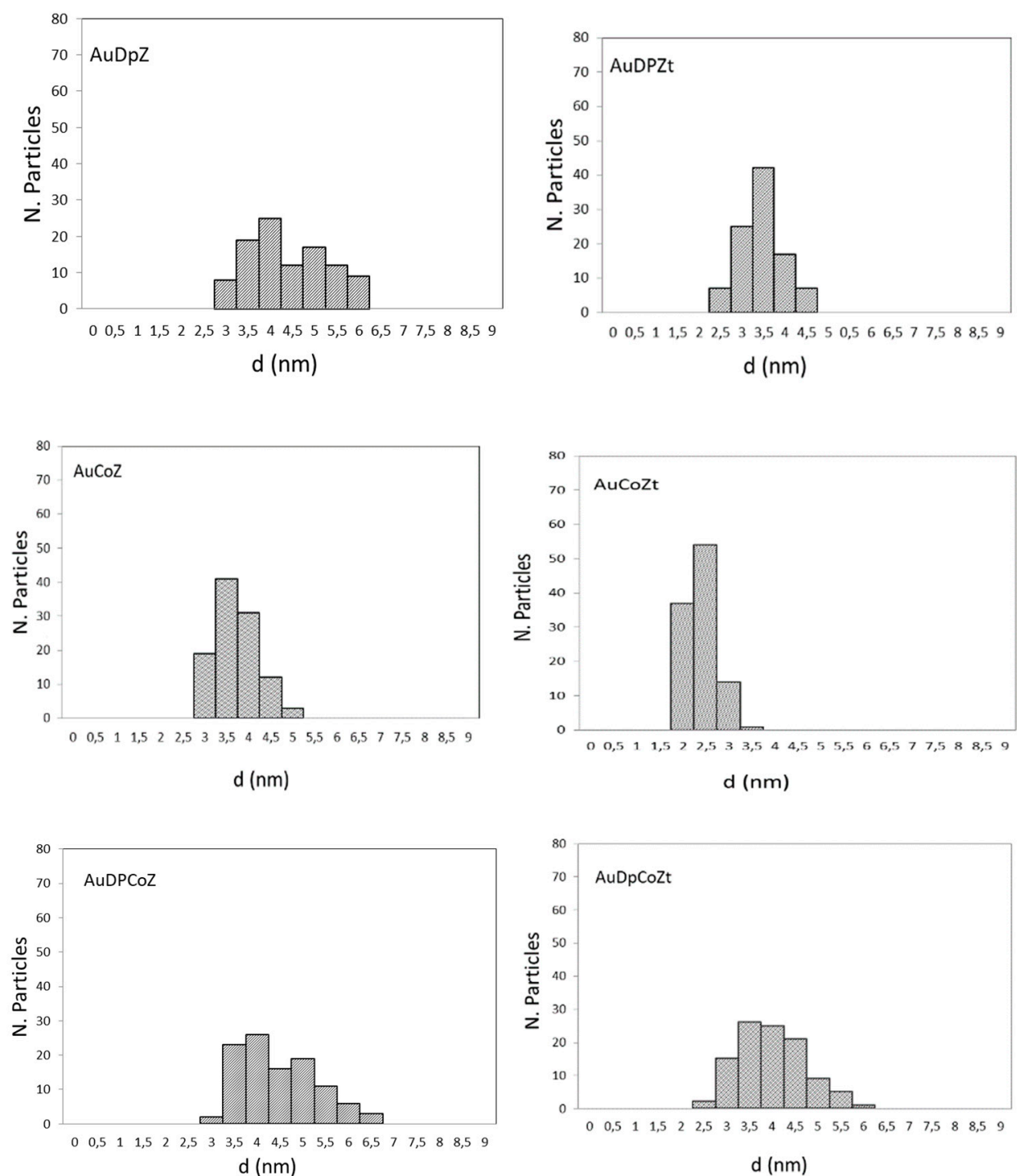

Figure 4. Particle size distribution histogram of gold nanoparticles.

According to the results, it can be concluded that the gold particle sizes in samples where zirconia adopts tetragonal structure are slightly smaller than those in zirconia with a monoclinic structure. Bimetallic catalysts prepared by the DP technique do not show significant differences in gold particle size with respect to catalysts containing only the precious metal in their formulation.

In order to analyze the gold effect on reducibility, temperature programmed reduction (TPR) analyses were performed. Catalysts containing only gold show no signals of reduction, evidencing that gold is found as a metallic species. Figure $5 \mathrm{~A}$ and $5 \mathrm{~B}$ show $\mathrm{H}_{2}$ consumption as a function of temperature for catalysts supported on monoclinic and hydrated zirconia, respectively. 

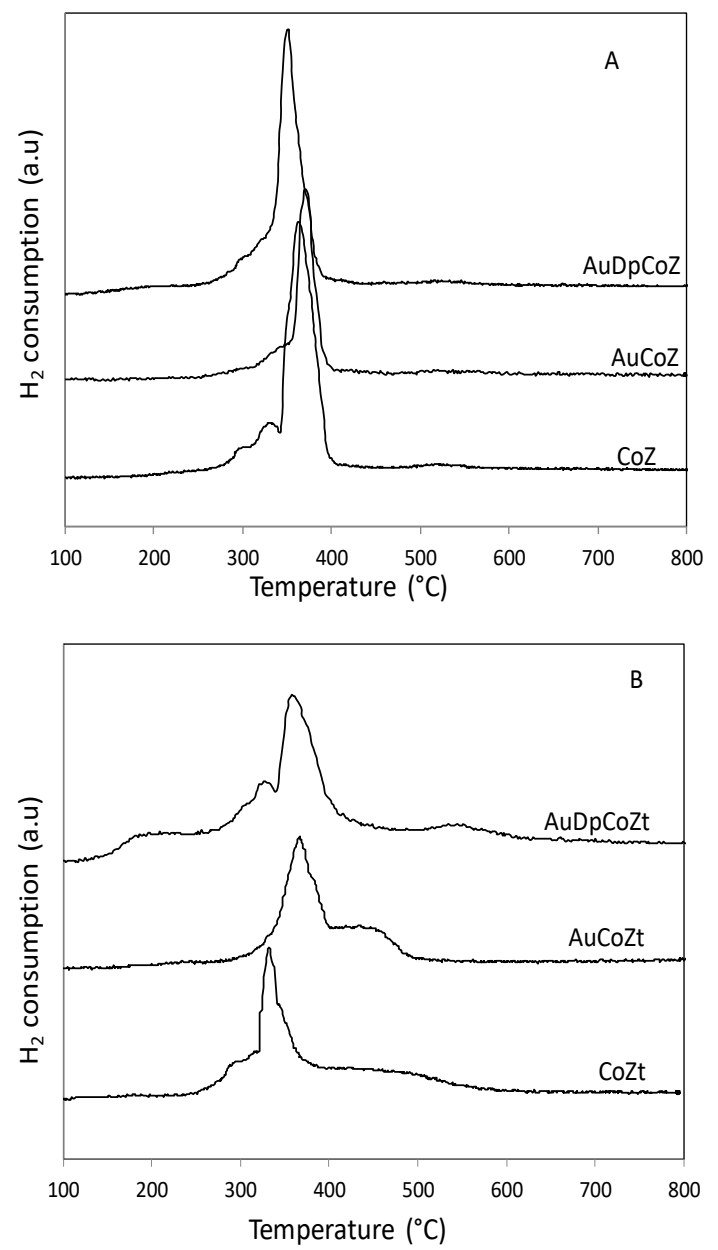

Figure 5. Temperature-programmed reduction diagrams of (A) monoclinic zirconia-supported catalysts and (B) tetragonal zirconia-supported catalysts.

The pure $\mathrm{Co}_{3} \mathrm{O}_{4}$ TPR profile is characterized by two reduction steps, assigned to $\mathrm{Co}$ (III)-Co(II) and $\mathrm{Co}(\mathrm{II})-\mathrm{Co}(0)$ (with maxima at $324^{\circ} \mathrm{C}$ and $397^{\circ} \mathrm{C}$ ) [29]. The TPR profiles of the catalysts under study show a series of signals in the range $300-400{ }^{\circ} \mathrm{C}$ for catalysts supported on monoclinic zirconia, and in the range $130-550^{\circ} \mathrm{C}$ for catalysts supported on hydrated zirconia. This indicates the presence of various types of cobalt oxide species, or species with different interactions with the support.

Moreover, it can be observed that gold addition using the traditional impregnation technique generates a slight shift towards higher reduction temperatures for CoZ and CoZt. Instead, the incorporation of gold by the DP method shifts the maxima of the reduction bands to lower temperatures. Notoriously, the AuDpCoZt catalyst begins to reduce at a lower temperature than those containing only cobalt. The precious metal presence favors the reduction in the catalyst prepared by DP method; this effect is not observed with the addition of gold by the traditional method. Furthermore, there are reduction signals at very low temperatures $\left(130^{\circ} \mathrm{C}\right)$, suggesting the presence of species with very low interaction with the support. The lower reduction temperature can be explained based on the small size of $\mathrm{Co}_{3} \mathrm{O}_{4}$ particles, as was observed by XRD, and/or on the interaction of transition metal species with the zirconia surface $[30,31]$. For this catalyst, both the support and the gold addition method favor the surface dispersion of the cobalt oxide, therefore increasing the reducibility. This fact also was reported by Solsona et al., who proposed that this reducibility enhancement is probably due to the formation of $\mathrm{Co}_{3} \mathrm{O}_{4}$ domains at the gold-CoOx interface perimeter [32].

In general, it can be observed that catalysts that preferably adopt a tetragonal structure are more reducible than catalysts prepared on a monoclinic support. In a research work using CuZ [33], it was reported that copper species reducibility increases in $\mathrm{ZrO}_{2}$, especially in tetragonal phase. It is 
suggested that during the calcination of hydrated zirconia to give anhydrous $\mathrm{ZrO}_{2}$, the $\mathrm{OH}^{-}$groups are responsible for the reduction of $\mathrm{Zr}^{4+}$ to $\mathrm{Zr}^{3+}$ ions, while the presence of a lower $\mathrm{Zr}$ oxidation state generates an increase in anionic vacancies. The vacancy effect of zirconia network affects the redox properties of supported oxide species, increasing the reducibility because these supported particles are in a reducing environment. It is worthwhile remarking that AuDpCoZt is the most reducible catalyst due to an earlier start in reducing the supported cobalt species. In this catalyst, two effects can be associated with the increase of the reducibility, the first one associated with the source zirconia and the second associated with the "disperser effect" of the gold added by the DP technique on the cobalt oxide.

X-ray photoelectron spectroscopy (XPS) was used to investigate the chemical state of surface species of catalysts. The multiregion XPS spectra of all gold-containing catalysts show binding energies of the doublet $\mathrm{Au} 4 f_{7 / 2}$ and $\mathrm{Au} 4 f_{5 / 2}$ at 83.6 and $87.2 \mathrm{eV}$, respectively, corresponding to metallic gold $\left(\mathrm{Au}^{0}\right)$, as reported in the literature [34] (the spectra of AuCoZt and AuDpCoZt catalysts are shown as Supplementary Material Figure S2). The presence of reduced gold species is evident in all samples promoted with gold, even those where Au diffraction lines could not be observed by XRD, probably due to their small size.In order to delve into the gold oxidation state a little further, the Au $4 f_{7 / 2}$ signal was deconvoluted for all catalysts under study. It is important to remark that as a component around $85.8 \mathrm{eV}$ and another one at $85.1 \mathrm{eV}$ corresponding to $\mathrm{Au}^{3+}$ and $\mathrm{Au}^{1+}$ are not observed, the presence of ionic gold in all the samples under study is discarded [34,35].

The Co $2 p$ core level cobalt spectra show the doublet Co $2 p_{3 / 2}$ and Co $2 p_{1 / 2}$ at about 781 and 795 $\mathrm{eV}$, respectively, with their respective shake-up satellites (Figure 6).
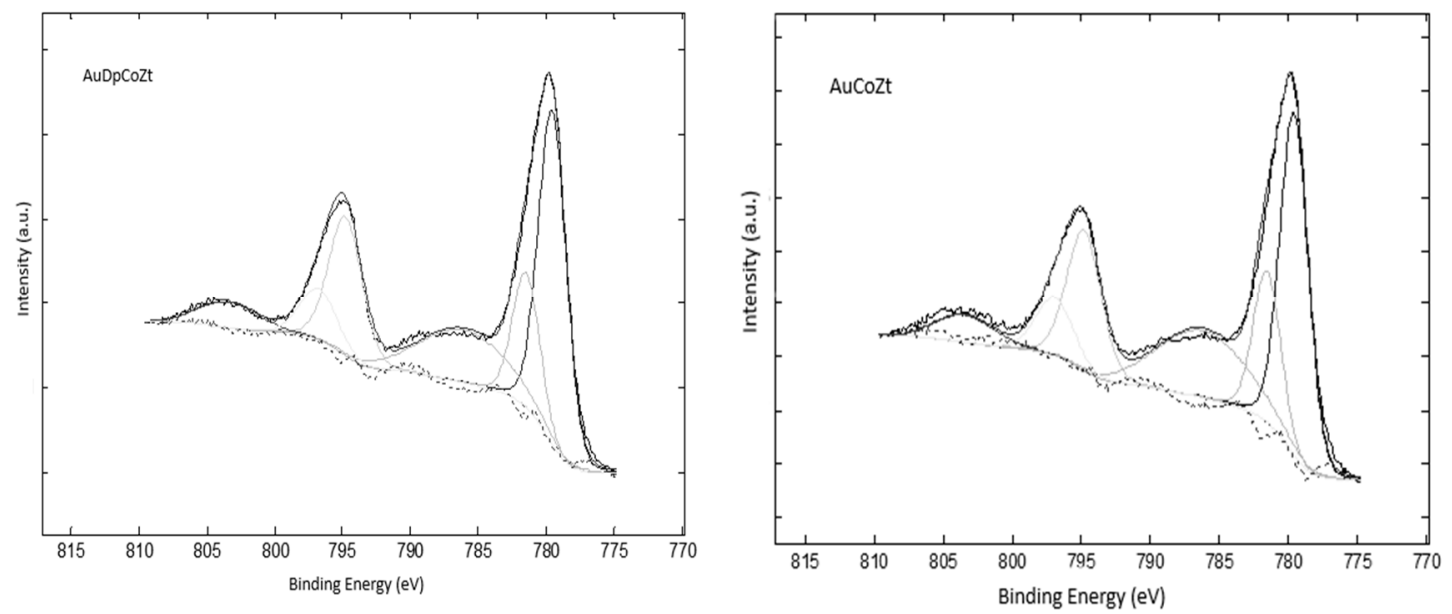

Figure 6. Co $2 p$ XPS spectra and deconvolution.

Table 2 shows the binding energies of peaks found in the Co $2 p$ core level spectra of bimetallic catalysts. The existence of satellite peaks is associated with the presence of paramagnetic species and, for this reason, this signal is associated with the presence of $\mathrm{Co}^{2+}$. The $\mathrm{Co}_{3} \mathrm{O}_{4}$ presents core level $2 p_{3 / 2}$ signals at $779.6 \mathrm{eV}$ of $\mathrm{Co}^{3+}$ and at $780.7 \mathrm{eV}$ of $\mathrm{Co}^{2+}[36,37]$.

Table 2. X-ray photoelectron spectroscopy results for catalysts (all values in $\mathrm{eV}$ ).

\begin{tabular}{ccccccc}
\hline Catalyst & Co $2 p_{\mathbf{3} / \mathbf{2}}$ & Co 2 $p_{\mathbf{3} / \mathbf{2} \text { sat }}$ & pp-sat & Co $2 p_{\mathbf{1 / 2}}$ & Co $2 p_{\mathbf{1 / 2} \text { sat }}$ & $\boldsymbol{\Delta} \mathrm{E}^{\mathbf{b}}$ \\
\hline AuCoZ & $779.7-781.6$ & 786.2 & 6.9 & 794.9 & 803.6 & 15.2 \\
AuDpCoZ & $779.7-781.6$ & 786.0 & 6.3 & 794.9 & 803.6 & 15.2 \\
AuCoZt & $779.5-781.5$ & 786.1 & 6.5 & 794.7 & 803.4 & 15.2 \\
AuDpCoZt & $779.7-781.6$ & 786.0 & 6.3 & 794.8 & 803.4 & 15.2 \\
\hline
\end{tabular}

${ }^{\mathrm{a}}$ Difference between main peak and satellite. ${ }^{\mathrm{b}}$ Difference of energy in the doublet Co $2 p_{3 / 2}$ and Co $2 p_{1 / 2 .}$. 
Table 2 shows that in all bimetallic catalysts, the binding energy is associated with the presence of $\mathrm{Co}_{3} \mathrm{O}_{4}$ species. The appearance of satellite peaks at about $6 \mathrm{eV}$ from the high energy component is further evidence for $\mathrm{Co}^{2+}$ [38]. It can also be observed that the difference in binding energy between $\mathrm{Co} 2 p_{3 / 2}$ and $\mathrm{Co} 2 p_{1 / 2}(\Delta \mathrm{E})$ is about $15 \mathrm{eV}$, indicating the coexistence of $\mathrm{Co}^{2+}$ and $\mathrm{Co}^{3+}$ [39].From the results presented, it is not appreciated that the gold addition method generates a change in the $\mathrm{BE}$ of the surface cobalt species.

Table 3 summarizes the surface atomic ratios, $\mathrm{Co} / \mathrm{Z}, \mathrm{Au} / \mathrm{Z}, \mathrm{Au} / \mathrm{Co}$, and $\mathrm{Co}^{2+} / \mathrm{Co}^{3+}$. When analyzing the $\mathrm{Au} / \mathrm{Z}$ and $\mathrm{Au} / \mathrm{Co}$ ratios, the solids synthesized by the DP method have a higher surface Au content compared to the ones synthesized by the traditional method. The same behavior is observed with the $\mathrm{Co} / \mathrm{Z}$ ratio. The catalytic activity can be influenced by the differences between cobalt and Au surface concentrations [40].It is noteworthy that the catalysts promoted with gold using the DP method show the highest $\mathrm{Co} / \mathrm{Z}$ and $\mathrm{Au} / \mathrm{Z}$ surface atomic ratios. The AuDPCoZt catalyst also exhibits the highest surface $\mathrm{Au} / \mathrm{Co}$ ratio, indicating that this catalyst has the highest concentration of surface gold. All catalysts present a similar $\mathrm{Co}^{2+} / \mathrm{Co}^{3+}$ ratio.

Table 3. XPS results: atomic ratios of catalysts.

\begin{tabular}{ccccc}
\hline Catalyst & $\mathbf{C o} / \mathbf{Z}$ & $\mathbf{A u} / \mathbf{Z}$ & $\mathbf{A u} / \mathbf{C o}$ & $\mathbf{C o}^{\mathbf{2 +}} / \mathbf{C o}^{\mathbf{3 +}}$ \\
\hline AuZ & - & 0.0143 & - & - \\
AuZt & - & 0.0008 & - & - \\
AuDpZ & - & 0.017 & - & - \\
AuDpZt & - & 0.0083 & - & 0.40 \\
AuCoZ & 1.4038 & 0.0247 & 0.0175 & 0.38 \\
AuDpCoZ & 2.5920 & 0.0547 & 0.0205 & 0.43 \\
AuCoZt & 0.7757 & 0.0225 & 0.0173 & 0.39 \\
AuDpCoZt & 2.0516 & 0.0613 & 0.0320 & \\
\hline
\end{tabular}

\subsection{Catalytic Activity}

2.2.1. Catalytic Combustion of Propane in the Presence of $\mathrm{O}_{2} / \mathrm{He}$

Propane combustion activity results for all catalysts presented in this paper are shown in Figures 7 and 8. These experiments were carried out using an $\mathrm{O}_{2} / \mathrm{He}$ mixture as oxidizing agent. Table 4 summarizes T50 and T100 values (temperature at which 50\% and $100 \%$ conversions are reached, respectively) obtained in each experiment.

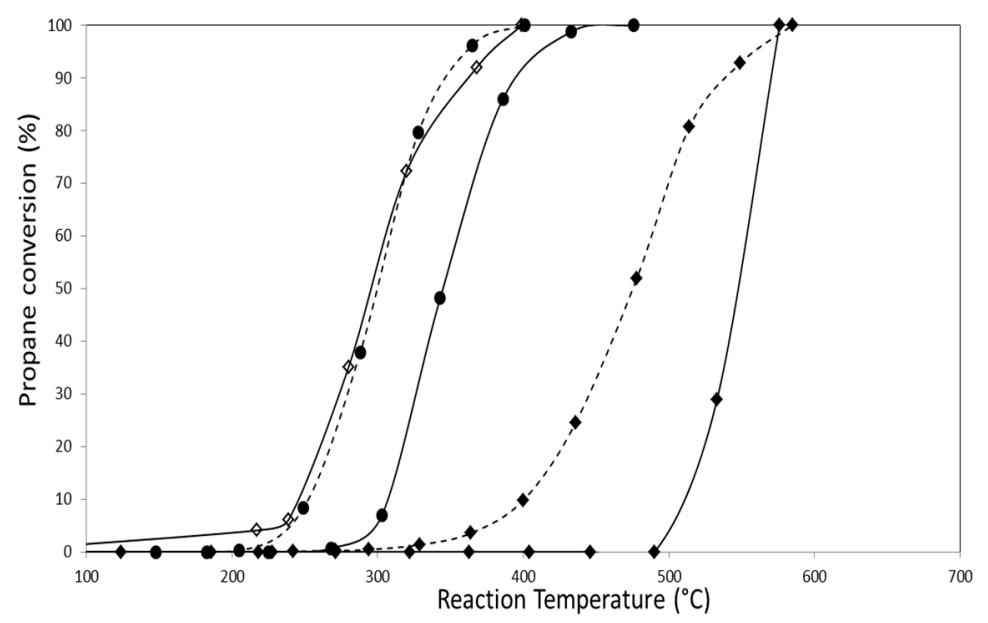

Figure 7. Results of propane conversion to $\mathrm{CO}_{2}$ of monoclinic zirconia-supported catalysts $(\diamond) \mathrm{CoZ},(\diamond)$ $\mathrm{AuZ},(\bullet) \mathrm{AuCoZ},(-\bullet) \mathrm{AuDpZ},(-\bullet-) \mathrm{AuDpCoZ}$. 


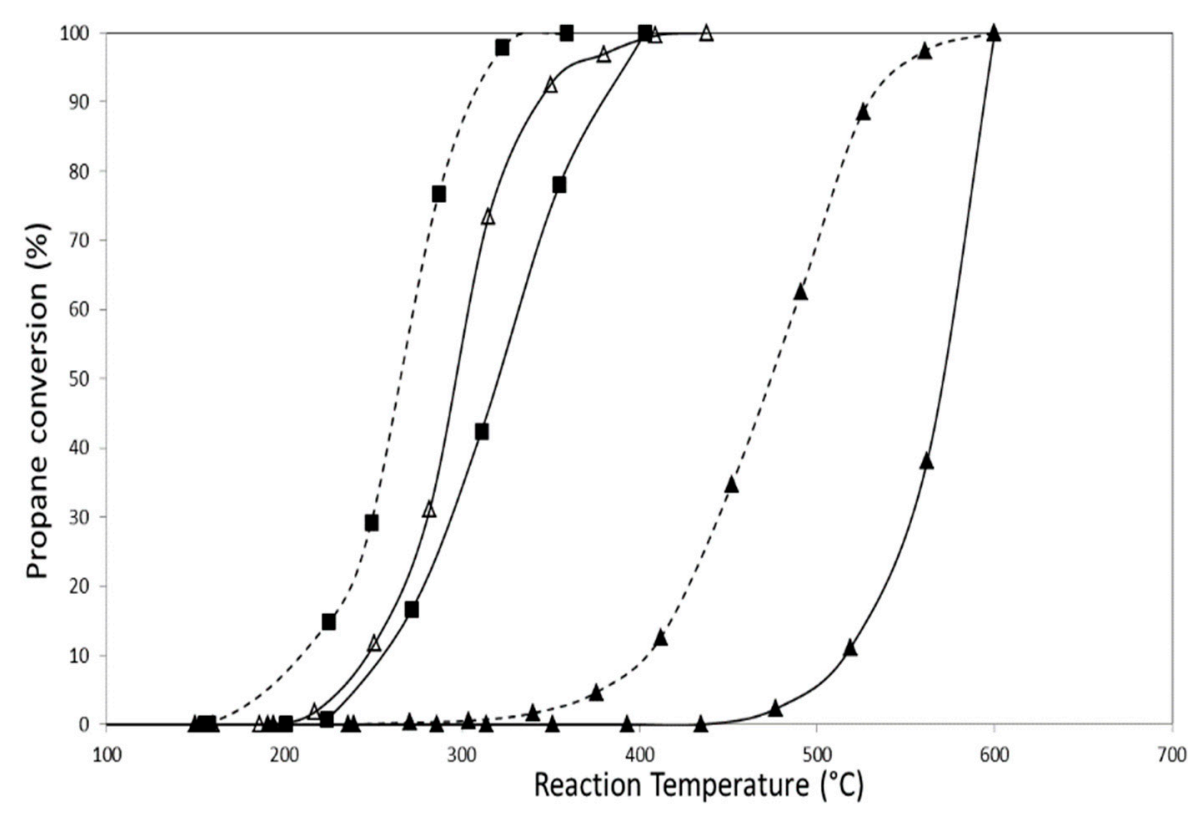

Figure 8. Results of propane conversion to $\mathrm{CO}_{2}$ of tetragonal zirconia-supported catalysts $(\Delta) \mathrm{CoZt},(\mathbf{\Lambda})$

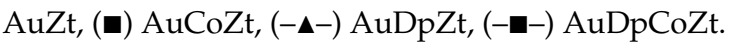

Table 4. T50 and T100 obtained with catalysts in propane combustion.

\begin{tabular}{ccc}
\hline \multirow{2}{*}{ Catalyst } & \multicolumn{2}{c}{ Propane Combustion } \\
\cline { 2 - 3 } & T50 $\left({ }^{\circ} \mathbf{C}\right)$ & T100 $\left({ }^{\circ} \mathbf{C}\right)$ \\
\hline $\mathrm{AuZ}$ & 550 & 576 \\
$\mathrm{AuZt}$ & 457 & 551 \\
$\mathrm{AuDpZ}$ & 478 & 585 \\
$\mathrm{AuDpZt}$ & 470 & 595 \\
$\mathrm{CoZ}$ & 300 & 400 \\
$\mathrm{CoZt}$ & 295 & 410 \\
$\mathrm{AuCoZ}$ & 342 & 442 \\
$\mathrm{AuDpCoZ}$ & 300 & 400 \\
$\mathrm{AuCoZt}$ & 320 & 410 \\
$\mathrm{AuDpCoZt}$ & 265 & 340 \\
\hline
\end{tabular}

Catalysts containing only gold in their formulation have low activity for the reaction, but it is noteworthy that they are more active than the pure support. Additionally, it can be observed that catalysts prepared from zirconia hydrogel (AuZt and AuDpZt) have greater activity (T50) than those prepared using commercial monoclinic zirconia. This fact is probably related to the larger surface area and smaller gold crystal size in catalysts supported on $\mathrm{Zt}$ zirconia.

Gold addition to the CoZ catalyst using the traditional impregnation technique causes an approximate shift of $40^{\circ} \mathrm{C}$ towards higher temperatures, decreasing the activity of this catalyst for propane combustion. A similar effect occurs when gold is added to CoZt catalyst, but only T50 is modified in this case, maintaining T100 value. These results may be associated with the reducibility decrease shown in TPR profiles in which a shift of the reduction signals towards higher temperature is observed for $\mathrm{AuCoZ}$ and AuCoZt.

Instead, gold addition to the CoZ catalyst employing DP technique leads to a slight increase in the catalyst activity, evidenced only at high conversions (>70\%) with a decrease of the T100. On the other hand, the presence of gold nanoparticles clearly produces an increase in the activity of the CoZt catalyst and the $\mathrm{T} 50$ decreases $\left(\sim 30^{\circ} \mathrm{C}\right)$. In this case, the noble metal addition promotes the activity, and the synergic effect between $\mathrm{Au}-\mathrm{Co}_{3} \mathrm{O}_{4}-\mathrm{ZrO}_{2}$ is more evident. 
It should be noted that the post-reaction catalysts were analyzed using the XPS technique, and no changes were found at the surface level with regard to the surface atomic ratios or the BE of the elements of the supported species. These results are shown in Supplementary Material Table S1.

From the results presented previously, it can be suggested that the catalytic cycle involves various factors that must be taken into account. On the one hand, the high activity of oxide cobalt, $\mathrm{Co}_{3} \mathrm{O}_{4}$, is evident, and this result is consistent with those widely reported in the literature. On the other hand, the role of the support is very important because it can participate in the redox cycles and, last but not least, the synergic effect of gold addition. Some aspects related to the physicochemical properties and the activity of the catalysts promoted with gold using the DP technique are discussed below.

The results must be analyzed taking into account that monometallic gold catalysts do not show good catalytic activity at low temperatures $\left(\mathrm{T}<400{ }^{\circ} \mathrm{C}\right)$. Changes in the nature of redox sites and higher availability of $\mathrm{Co}_{3} \mathrm{O}_{4}-\mathrm{Au}^{0}$ supported phases may explain differences in the activity of $\mathrm{AuDpCoZ}$ and $\mathrm{AuDpCoZt}$ catalysts. In the AuDpCoZt catalyst, gold addition generates a promoting effect, reaching a $\mathrm{T} 50$ at $265^{\circ} \mathrm{C}$, which is a good propane combustion temperature and, in this catalyst, gold generates a greater beneficial synergic effect than in AuDpCoZ. According to XPS results, it is observed that the $\mathrm{AuDpCoZ}$ catalyst presents higher surface cobalt content than the AuDpCoZt catalyst. Despite this, the AuDpCoZt catalyst is the one with the highest surface content of Au of the series; this sample also presents a higher content of exposed gold according to the $\mathrm{Au} / \mathrm{Zr}$ and $\mathrm{Au} / \mathrm{Co}$ ratios (Table 3). Therefore, the best catalytic performance observed for AuDpCoZt can be attributed to the presence of a high surface concentration of cobalt and gold. There is also a beneficial interaction between oxide cobalt and gold nanoparticles that promotes $\mathrm{Co}_{3} \mathrm{O}_{4}$ dispersion and consequently increases the system reducibility. It is important to remark that this synergism is not observed when gold was added using the traditional impregnation technique. Solsona et al. [41] reported the gold promoting effect of cobalt catalysts supported on mesoporous silica in the total oxidation of propane and toluene. They concluded that the presence of gold generates higher reducibility of certain cobalt species, which facilitates the redox cycle.

In this context, it is also important to highlight the influence of the support. The most active catalyst is that obtained from the high surface area hydrogel used as zirconia source. In this catalyst, zirconia adopts the metastable tetragonal structure and oxygen vacancies are generated. The presence of zirconia oxygen vacancies favors these processes because the reducibility of species increases, as was observed by TPR results. $\mathrm{Au}-\mathrm{Co}_{3} \mathrm{O}_{4}$ domains intimately interacting with the support can promote oxygen lattice mobility, which can increase the activity. Moreover, the greater metal-zirconia interaction favors the formation of vacancies in the bulk, and consequently, facilitates the movement of oxygen in the catalytic system from the bulk to the surface.

It has been reported in the literature that one of the most accepted mechanisms in the catalytic oxidation of hydrocarbons is the Mars-van Krevelen (MVK) mechanism [42]. In this mechanism, it is postulated that the metallic oxide provides the active oxygen for the reaction and generates a redox cycle where $\mathrm{Co}(\mathrm{III})$ can be reduced to $\mathrm{Co}(\mathrm{II})$ [17]. Solsona et al. [43] studied propane oxidation in the absence of oxygen using a $\mathrm{CuOx}-\mathrm{CeO}_{2}$ catalyst, and observed $\mathrm{CO}_{2}$ as reaction product only, indicating lattice oxygen participation. Another accepted mechanism for the catalytic combustion of hydrocarbons is the Langmuir-Hinshelwood mechanism [44]. This one implies the existence of active adsorption sites where the reagents interact and become products. As the zirconia has oxygen vacancies, they can be adsorption sites of reactants (oxygen or hydrocarbons). The $\mathrm{O}_{2}$ adsorption can be explained by the involvement of $\mathrm{Zr}^{3+} / \mathrm{Zr}^{4+}$ redox cycles and the formation of $\mathrm{O}^{2-}$ ads [30]. According to the results obtained in this work, both mechanisms can contribute to the catalytic activity. In this context, and in agreement with what is reported in the literature $[18,40,41]$, the role of gold can be associated with an enhancement of the cobalt species reducibility, which facilitates the redox cycle. The role of gold has been associated with a promoting effect of reoxidation or recovery of the cobalt oxide during the redox cycle $[18,41]$. 
2.2.2. Catalytic Combustion of Propane in the Presence of $\mathrm{O}_{2} / \mathrm{NO} / \mathrm{He}$

The activity of catalysts in the presence of nitrogen oxides was also measured as this pollutant is commonly found in emissions from mobile sources. The results obtained using the same previous operating conditions with the addition of 1000 ppm of NO to the feed are shown in Figures 9 and 10.

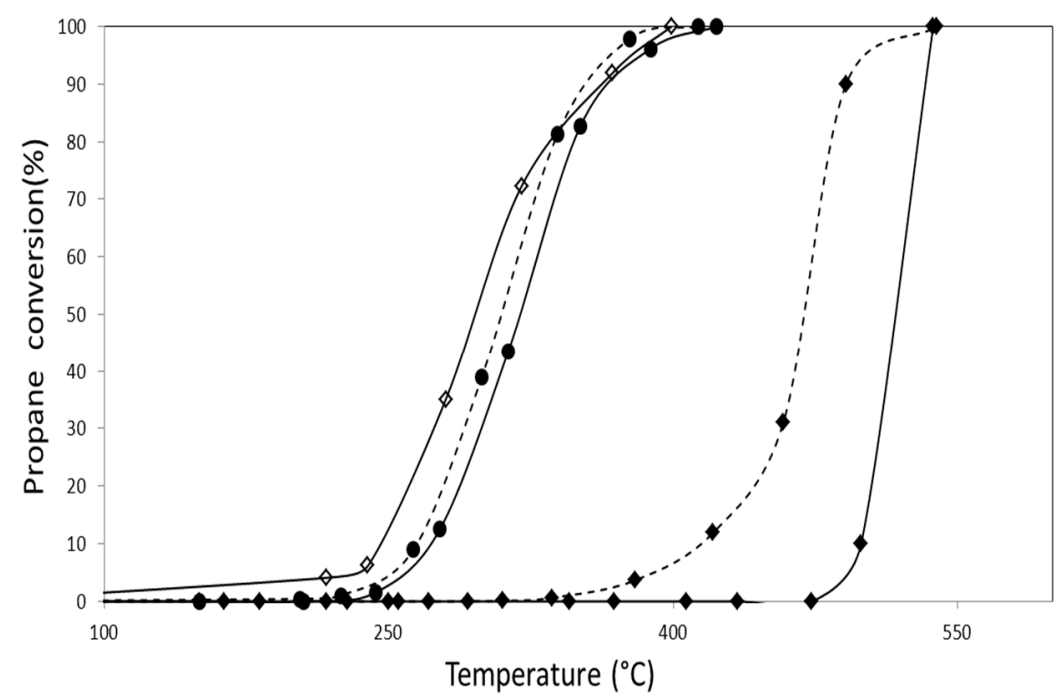

Figure 9. Propane combustion using a mixture of $\mathrm{NO}, \mathrm{O}_{2}$ and $\mathrm{He}$ as oxidizing agent for the catalysts $(\diamond) \mathrm{CoZ},(\diamond) \mathrm{AuZ},(\bullet) \mathrm{AuCoZ},(-\bullet) \mathrm{AuDpZ},(-\bullet-) \mathrm{AuDpCoZ}$

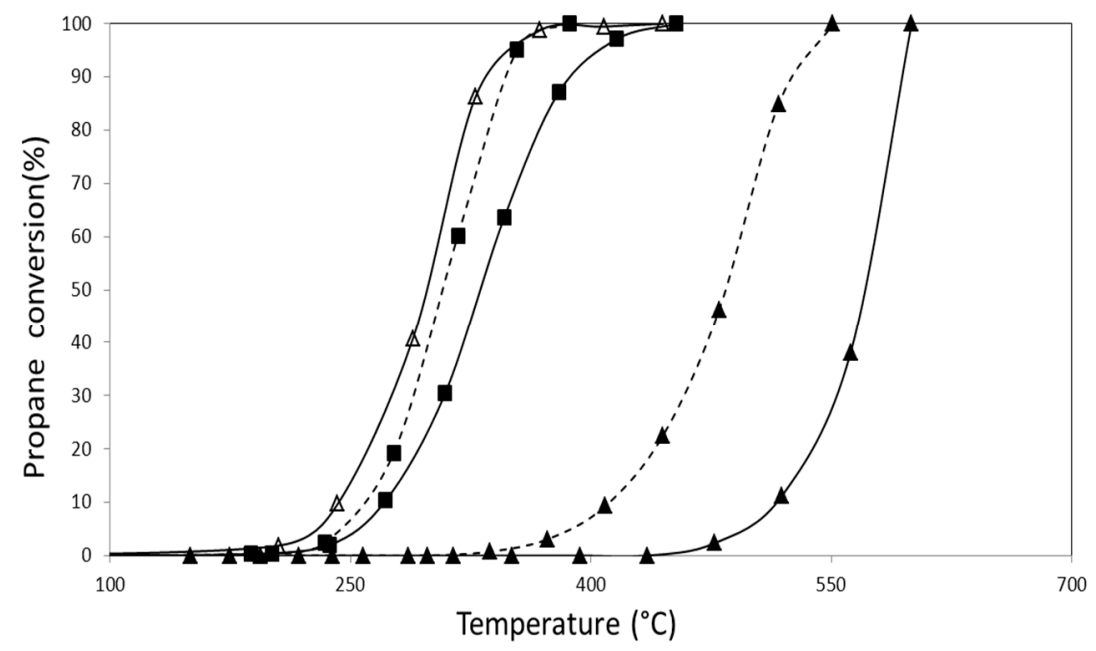

Figure 10. Propane combustion using a mixture of $\mathrm{NO}, \mathrm{O}_{2}$ and $\mathrm{He}$ as oxidizing agent for the catalysts $(\Delta) \mathrm{CoZt},(\mathbf{\Delta}) \mathrm{AuZt},(\mathbf{\square}) \mathrm{AuCoZt},(-\mathbf{\Delta}-) \mathrm{AuDpZt},(-\mathbf{-}-) \mathrm{AuDpCoZt}$.

The results of the catalysts supported on monoclinic zirconia show that the presence of NO in gold catalysts favors the activity, using T50 as a comparison parameter. On the other hand, in the case of monometallic catalysts containing cobalt, the presence of NO poses a slight disadvantage (Table 5). In bimetallic systems, these two opposite effects could coexist and lead to an increase or decrease in the activity. 
Table 5. T50 obtained with catalysts in propane combustion with and without nitric oxide (NO).

\begin{tabular}{ccc}
\hline \multirow{2}{*}{ Catalyst } & \multicolumn{2}{c}{ Propane Combustion } \\
\cline { 2 - 3 } & $\mathbf{T 5 0}\left({ }^{\circ} \mathbf{C}\right)$ in NO Absence & T50 $\left({ }^{\circ} \mathbf{C}\right)$ in NO Presence \\
\hline $\mathrm{AuZ}$ & 550 & 520 \\
$\mathrm{AuDpZ}$ & 478 & 465 \\
$\mathrm{CoZ}$ & 300 & 305 \\
$\mathrm{AuCoZ}$ & 342 & 320 \\
$\mathrm{AuDpCoZ}$ & 300 & 308 \\
$\mathrm{AuZt}$ & 457 & 515 \\
$\mathrm{AuDpZt}$ & 470 & 480 \\
$\mathrm{CoZt}$ & 295 & 320 \\
$\mathrm{AuCoZt}$ & 320 & 330 \\
$\mathrm{AuDpCoZt}$ & 265 & 305 \\
\hline
\end{tabular}

The greatest positive effect of gold occurs in the AuCoZ catalyst, leading to a catalyst with increased activity due to the addition of NO to the feed. On the other hand, in the AuDpCoZ catalyst, the cobalt depressor effect prevails, leading to a less active catalyst in the presence of $\mathrm{NO}$ (T50).

It should be noted that in the presence of $\mathrm{NO}$, the only system that shows a slight increase in activity when gold is added is $\mathrm{CoZt}\left(\mathrm{T} 50=320^{\circ} \mathrm{C}\right)$ promoted by the DP method $\left(\mathrm{T} 50=305^{\circ} \mathrm{C}\right)$.

In the case of catalysts prepared from the hydrogel (Figure 10), the effect of NO is negative for the activity of both monometallic gold and cobalt catalysts. This effect is transferred to bimetallic catalysts regardless of the gold addition method.

Differences in catalytic behavior in the presence of $\mathrm{NO}$ could be attributed to prior oxidation of $\mathrm{NO}$ to $\mathrm{NO}_{2}$ (which is a better oxidant), or to competitive $\mathrm{NO}$ adsorption at the sites where the reactants are adsorbed (hydrocarbon or oxygen).

\subsubsection{Catalytic Combustion of Naphthalene}

The results for naphthalene combustion are presented in Table 6 . Naphthalene is oxidized at a very high temperature in the absence of catalyst with $\mathrm{T} 50=440{ }^{\circ} \mathrm{C}$ and $\mathrm{T} 100=490^{\circ} \mathrm{C}$. The catalysts decrease these temperatures considerably, indicating that they are active for naphthalene catalytic combustion. According to catalytic results, it can be observed that monometallic cobalt catalysts are more active than gold catalysts. In addition, by comparing gold catalysts, it can be seen that AuDpZ and AuDpZt are much more active than $A u Z$ and AuZt. Once again, it can be seen that the catalysts prepared using the DP method show higher activity than the catalysts prepared by the traditional method.

Table 6. T50 and T100 obtained with catalysts in naphthalene combustion.

\begin{tabular}{ccc}
\hline \multirow{2}{*}{ Catalyst } & \multicolumn{2}{c}{ Naphthalene Combustion } \\
\cline { 2 - 3 } & T50 $\left({ }^{\circ} \mathbf{C}\right)$ & T100 $\left({ }^{\circ} \mathbf{C}\right)$ \\
\hline AuZ & 310 & 400 \\
AuZt & 300 & 370 \\
AuDpZ & 259 & 340 \\
AuDpZt & 230 & 300 \\
CoZ & 190 & 275 \\
CoZt & 205 & 300 \\
AuCoZ & 210 & 350 \\
AuDpCoZ & 210 & 340 \\
AuCoZt & 195 & 350 \\
AuDpCoZt & 195 & 260 \\
\hline
\end{tabular}

In general terms, gold addition using the traditional method does not lead to an increase in the activity of the $\mathrm{CoZ}$ and CoZt catalysts. The CoZ catalyst is very active, and gold addition does not 
increase its activity. However, the high activity of gold deposited by the DP technique on the CoZt catalyst is noticeable. When the species are supported on tetragonal zirconia, of greater surface area, gold and cobalt present a synergic effect and this catalyst, AuDpCoZt, is the most active, achieving total naphthalene conversion to $\mathrm{CO}_{2}$ at $260^{\circ} \mathrm{C}$, which is a very good combustion temperature.Again, as was observed for propane combustion, the synergic effect between gold and cobalt species present in the AuDpCoZt catalyst is noteworthy.

It should be noted that the presence of carbonaceous residues in the catalytic processes studied (XPS not shown) is discarded, and the only product observed is $\mathrm{CO}_{2}$, which indicates a selectivity greater than $99 \%$.

There is almost no literature research on total naphthalene oxidation using supported gold- $-\mathrm{Co}_{3} \mathrm{O}_{4}$ catalysts, even though these systems were used for the combustion of other aromatic hydrocarbons such as toluene and benzene [45].

\section{Materials and Methods}

\subsection{Catalyst Preparation and Characterization}

Two supports were used to prepare the catalysts, zirconium oxide crystallized in monoclinic phase $\left(\mathrm{ZrO}_{2}\right)$ and amorphous hydrated zirconium oxide $\left(\mathrm{ZrO}_{2} \cdot \mathrm{nH}_{2} \mathrm{O}\right)$ prepared at the laboratory. Hydrated zirconium oxide $\left(\mathrm{ZrO}_{2} \cdot \mathrm{nH}_{2} \mathrm{O}\right)$ was obtained by hydrolysis of zirconium oxychloride, $\mathrm{ZrOCl}_{2} \cdot 6 \mathrm{H}_{2} \mathrm{O}$ (Fluka, Buchs, Switzerland). The necessary amount of ammonium hydroxide was added to zirconium oxychloride (up to $\mathrm{pH}=10$ ). The product obtained by hydrolysis was filtered and washed until complete elimination of chloride ions, as determined by the silver nitrate test. Finally, the solid obtained was dried at $80^{\circ} \mathrm{C}$ for $24 \mathrm{~h}$.

The other support, $\mathrm{ZrO}_{2}$, with established crystalline phase, was a commercial product provided by Anedra (Buenos Aires, Argentina). In order to differentiate the supports, $\mathrm{Z}$ and $\mathrm{Zt}$ were used for commercial zirconia and hydrated zirconia, respectively.

The catalysts containing gold in their formulation were prepared by two methods: support impregnation and deposit/precipitation method. A gold solution $(1 \% \mathrm{w} / \mathrm{v})$ was prepared from chloroauric acid trihydrate, $\mathrm{HAuCl}_{4} \cdot 3 \mathrm{H}_{2} \mathrm{O}$ (Sigma-Aldrich, Darmstadt, Germany). This solution was added to the support $(\mathrm{Z}$ or $\mathrm{Zt})$, achieving the necessary volume to get a nominal gold concentration of $1 \% \mathrm{w} / \mathrm{w}$ in the catalyst. For the first method, the supports were impregnated with the gold solution with intermediate drying. In the case of preparation by the DP method, the support was suspended in an alkaline aqueous solution $(5 \mathrm{M} \mathrm{NaOH})$ with permanent agitation at $80^{\circ} \mathrm{C}$ and $\mathrm{pH}=8$; the gold solution was added, aged for $2 \mathrm{~h}$, and then it was filtered and washed until the absence of $\mathrm{Cl}^{-}$ions.

For the preparation of the precursors containing cobalt, cobalt nitrate hexahydrate salt, $\mathrm{Co}\left(\mathrm{NO}_{3}\right)_{2} \cdot 6 \mathrm{H}_{2} \mathrm{O}$ (May \& Baker, London, United Kingdom), was used. The impregnation of supports was carried out with an aqueous solution of the cobalt salt in ammoniacal medium ( $\mathrm{pH} \sim 10)$, inrotavapor equipment at $100{ }^{\circ} \mathrm{C}$, at a rate of $170 \mathrm{rpm}$ and a vacuum pressure of $500 \mathrm{mmHg}$. The obtained solids were dried for $2 \mathrm{~h}$ at $100{ }^{\circ} \mathrm{C}$. The materials were prepared with a nominal concentration of $5 \% \mathrm{w} / \mathrm{w}$ in cobalt.

Gold precursors were prepared by adding gold to cobalt-containing precursors (CoZ and CoZt) using traditional impregnation and DP techniques.

The AuDp nomenclature indicates that gold was deposited by the deposit/precipitation technique. The catalysts were obtained by calcination of precursors for $2 \mathrm{~h}$ at $600{ }^{\circ} \mathrm{C}$ and were called:CoZ, CoZtAuZ, AuZt, AuCoZ, AuCoZt, AuDpZ, AuDpZt, AuDpCoZ, and AuDpCoZt.

\subsection{Catalyst Characterization}

The specific surface areas of catalysts were determined by the BET technique using a Micromeritics Accusorb 2100 E instrument (Micromeritics, Norcross, GA, USA). 
The micrographs of the samples were obtained by scanning electron microscopy (SEM) using Philips 505 Model equipment (Philips Co, Amsterdam, The Netherlands) provided with an EDAX DX PRIME 10 (EDAX, New Jersey, NJ, USA) energy dispersive X-ray analyzer.

Powder X-ray diffraction was used to identify the crystalline phases in the solid. A Philips PW 1732/10 diffractometer, with monochromatic $\mathrm{Cu} \mathrm{K} \alpha$ radiation (1.5378 $\AA$ ) operated at $40 \mathrm{kV}$ and $20 \mathrm{~mA}$, was used.

Transmission electron microscopy studies were carried out using a JEOL 100 CX II (Jeol Ltd., München, Germany) instrument. The samples were ground and ultrasonically dispersed in distilled water. To estimate the mean particle size, the particles were considered to be spherical and the expression used for the calculation was:

$$
d=\frac{\sum n_{i} d_{i}}{\sum n_{i} d_{i}}
$$

where $n_{i}$ is the number of particles of $d_{i}$ size. Over 100 particles were measured.

Temperature-programmed reduction experiments were carried out with conventional equipment. The reduction was performed using a gas mixture of $10 \%$ hydrogen in nitrogen (flow rate $20 \mathrm{~cm}^{3}$ $\mathrm{min}^{-1}$ ) with a heating rate of $10^{\circ} \mathrm{C} / \mathrm{min}$ up to $800{ }^{\circ} \mathrm{C}$. The amount of sample loaded was $30 \mathrm{mg}$.

$\mathrm{X}$-ray photoelectron spectroscopy analyses were performed with a spectrometer Physical Electronics PHI-5700 (Minneapolis, USA) equipped with a dual X-ray source of Mg K (1253.6 eV) and $\mathrm{Al} \mathrm{K}(1486.6 \mathrm{eV})$ and a multichannel detector. Spectra of powdered samples were recorded in the constant pass energy mode at $29.35 \mathrm{eV}$. Charge referencing was measured against adventitious carbon (C $1 s$ at $284.8 \mathrm{eV}$ ). A PHI ACCESS ESCA-V6.0 F software package was used for data acquisition and analysis. A Shirley-type background was subtracted from the signals. Recorded spectra were always fitted using Gaussian-Lorentzian curves in order to determine the binding energy of the different element core levels more accurately.

\subsection{Catalytic Activity}

\subsubsection{Propane Oxidation}

Catalysts were evaluated in an electrically heated fixed-bed quartz reactor containing $0.100 \mathrm{~g}$ of catalyst. The temperature was measured by means of a K-type thermocouple. The catalytic activity for propane oxidation was determined using a mixture of $\mathrm{NO} / \mathrm{He}, \mathrm{C}_{3} \mathrm{H}_{8} / \mathrm{He}, \mathrm{O}_{2} / \mathrm{He}$, and $\mathrm{He}$ to close the balance. The reaction flow contained 0 or $1000 \mathrm{ppm} \mathrm{NO}, 1000 \mathrm{ppm} \mathrm{C}_{3} \mathrm{H}_{8}$, and $8 \% v / v \mathrm{O}_{2}$ (total flow rate $=50 \mathrm{~cm}^{3} \mathrm{~min}^{-1}$ ). Reaction products were monitored with a TCD Shimadzu GC (GC 2014). The separation of products was performed with an Alltech CTRI concentric column. A schematic diagram of the reaction system was reported in a previous work [24]. Propane conversion was calculated using the expression:

$$
\mathrm{XCO}=1 / 3\left[\mathrm{CO}_{2}\right] /\left[\mathrm{C}_{3} \mathrm{H}_{8}\right]
$$

where $\left[\mathrm{CO}_{2}\right]$ is gas-phase concentration after reaction and $\left[\mathrm{C}_{3} \mathrm{H}_{8}\right]$ is feed concentration. The carbon balance in the measurements was better than $98 \%$.

\subsubsection{Naphthalene Oxidation}

Catalysts were evaluated in an electrically heated fixed-bed quartz reactor containing $0.100 \mathrm{~g}$ of catalyst. The catalytic activity for naphthalene oxidation was determined using a mixture of $10 \%$ $v / v \mathrm{O}_{2}, 90 \% v / v \mathrm{He}$, and $150 \mathrm{ppm}$ naphthalene. The total flow rate was $30 \mathrm{~cm}^{3} \mathrm{~min}^{-1}$. Products were analyzed using a Shimadzu gas chromatograph, model GC 2014, with a thermal conductivity detector. To achieve a stable concentration of naphthalene in the gas phase, the input current passed through a thermostated saturator containing this reactant.

Despite this, the combustion experiment was initiated as soon as a stable vapor pressure was reached. As the system must reach equilibrium at each reaction temperature, to ensure the result, 
several analyses were performed at each temperature. A schematic diagram of the reaction system is shown in a previous work [23].

Naphthalene conversion was calculated using the expression:

$$
\mathrm{XCO}_{2}=1 / 10\left[\mathrm{CO}_{2}\right] /\left[\mathrm{C}_{10} \mathrm{H}_{8}\right]
$$

where $\left[\mathrm{CO}_{2}\right]$ is gas-phase concentration after reaction and $\left[\mathrm{C}_{10} \mathrm{H}_{8}\right]$ is feed concentration.

\section{Conclusions}

The preparation method of monometallic gold catalysts directly influences the activity of these solids, both for propane and naphthalene reactions. Catalysts prepared using the DP method have better activity than those in which the traditional technique is used (except for AuZt and AuDpZt).

In both propane and naphthalene combustion reactions, the obtained results indicate that catalysts formulated with $\mathrm{Co}_{3} \mathrm{O}_{4}$ are more active than those containing only $\mathrm{Au}$. It was also demonstrated that gold addition using the DP method leads to obtaining more active catalysts.Gold metal addition generates an important promoting effect on the AuDpCoZt catalyst, which was prepared from a hydrous zirconia. This solid presents the highest surface Au content of the studied series, as well as a high amount of surface cobalt. The catalytic behavior of this sample is associated with a synergic effect between gold and cobalt, which is also evidenced by an increase in the reducibility of this catalytic system.

Supplementary Materials: The following are available online at http://www.mdpi.com/2073-4344/10/4/387/s1, Figure S1: TEM micrograph of catalysts, Figure S2: XPS Au 4f spectra and deconvolution. Table S1 XPS results. $\mathrm{Au} / \mathrm{Co}$ and $\mathrm{Au} / \mathrm{Z}$ atomic ratios of fresh and post-reaction catalysts.

Author Contributions: I.D.L. and M.I.P. conceived and designed the experiments; M.S.L.A., M.L.R., and M.A.O. performed the experiments; E.R.-C. contributed with XPS spectroscopy measurements and analysis, all authors discussed the results; I.D.L. and M.S.L.A. wrote the manuscript. All authors read, revised, and approved the final manuscript. All authors have read and agreed to the published version of the manuscript.

Acknowledgments: The authors acknowledge the financial support of CONICET, ANPCyT and UNLP; Mrs. Mariela Theiller for SEM-EDS measurements and Dr. María Laura Barbelli for collaborations. E.R.C. thanks project RTI2018-099668-BC22 of Ministerio de Ciencia, Innovación y Universidades, and project UMA18-FEDERJA-126 of Junta de Andalucía and FEDER funds.

Conflicts of Interest: The authors declare no conflict of interest.

\section{References}

1. Aranda, A.; López, J.M.; Murillo, R.; Mastral, A.M.; Dejoz, A.; Vázquez, I.; Solsona, B.; Taylor, S.H.; García, A.M.D. Total oxidation of naphthalene with high selectivity using a ceria catalyst prepared by a combustion method employing ethylene glycol. J. Hazard. Mater. 2009, 171, 393-399. [CrossRef]

2. Genuino, H.C.; Dharmarathna, S.; Njagi, E.C.; Mei, M.C.; Suib, S.L. Gas-Phase Total Oxidation of Benzene, Toluene, Ethylbenzene, and Xylenes Using Shape-Selective Manganese Oxide and Copper Manganese Oxide Catalysts. J. Phys. Chem. C 2012, 116, 12066-12078. [CrossRef]

3. Aparicio, M.S.L.; Lick, I.D. Total oxidation of propane and naphthalene from emission sources with supported cobalt catalysts. React. Kinet. Mech. Catal. 2016, 119, 469-479. [CrossRef]

4. He, C.; Cheng, J.; Zhang, X.; Douthwaite, M.; Pattisson, S.; Hao, Z. Recent Advances in the Catalytic Oxidation of Volatile Organic Compounds: A Review Based on Pollutant Sorts and Sources. Chem. Rev. 2019, 119, 4471-4568. [CrossRef]

5. Haruta, M.; Kobayashi, T.; Sano, H.; Yamada, N. Novel gold catalysts for the oxidation of carbon monoxide at a temperature far below 0.DEG.C. Chem. Lett. 1987, 405-408. [CrossRef]

6. Haruta, M. Gold catalysts prepared by coprecipitation for low-temperature oxidation of hydrogen and of carbon monoxide. J. Catal. 1989, 115, 301-309. [CrossRef]

7. Bond, G.C.; Louis, C.; Thompson, D.T. Catalysis by Gold; Imperial College Press: London, UK, 2006; pp. 4105-4108. 
8. Wu, P.; Loh, K.P.; Zhao, X.S. Supported Gold Catalysts for Selective Oxidation of Organics. Sci. Adv. Mater. 2011, 3, 970-983. [CrossRef]

9. De Almeida, M.P.; Martins, L.M.D.R.S.; Carabineiro, S.A.C.; Lauterbach, T.; Rominger, F.; Hashmi, A.S.K.; Pombeiro, A.J.L.; Figueiredo, J.L. Homogeneous and heterogenised new gold C-scorpionate complexes as catalysts for cyclohexane oxidation. Catal. Sci. Technol. 2013, 3, 3056-3069. [CrossRef]

10. Ribeiro, A.P.C.; Martins, L.M.D.R.S.; Carabineiro, S.; Figueiredo, J.L.; Pombeiro, A.J.L. Gold nanoparticles deposited on surface modified carbon materials as reusable catalysts for hydrocarboxylation of cyclohexane. Appl. Catal. A: Gen. 2017, 547, 124-131. [CrossRef]

11. Gluhoi, A.C.; Bogdanchikova, N.; Nieuwenhuys, B.E. Total oxidation of propene and propane over gold-copper oxide on alumina catalysts. Catal. Today 2006, 113, 178-181. [CrossRef]

12. Haruta, M. Size- and support-dependency in the catalysis of gold. Catal. Today 1997, 36, 153-166. [CrossRef]

13. Gluhoi, A.; Bogdanchikova, N.; Nieuwenhuys, B. The effect of different types of additives on the catalytic activity of $\mathrm{Au} / \mathrm{Al} 2 \mathrm{O} 3$ in propene total oxidation: Transition metal oxides and ceria. J. Catal. 2005, 229, 154-162. [CrossRef]

14. Scirè, S.; Liotta, L.F. Supported gold catalysts for the total oxidation of volatile organic compounds. Appl. Catal. B Environ. 2012, 125, 222-246. [CrossRef]

15. Trigueiro, F.; Ferreira, C.; Volta, J.-C.; Gonzalez, W.; De Oliveria, P.P. Effect of niobium addition to Co/ $\gamma-\mathrm{Al} 2 \mathrm{O} 3$ catalyst on methane combustion. Catal. Today 2006, 118, 425-432. [CrossRef]

16. Solsona, B.; García, T.; Hutchings, G.J.; Taylor, S.H.; Makkee, M. TAP reactor study of the deep oxidation of propane using cobalt oxide and gold-containing cobalt oxide catalysts. Appl. Catal. A Gen. 2009, 365, 222-230. [CrossRef]

17. Solsona, B.; Garcia, T.; Jones, C.; Taylor, S.H.; Carley, A.; Hutchings, G. Supported gold catalysts for the total oxidation of alkanes and carbon monoxide. Appl. Catal. A Gen. 2006, 312, 67-76. [CrossRef]

18. Ali, A.M.; Daous, M.A.; Khamis, A.A.; Driss, H.; Burch, R.; Petrov, L. Strong synergism between gold and manganese in an Au-Mn/triple-oxide-support (TOS) oxidation catalyst. Appl. Catal. A Gen. 2015, 489, $24-31$. [CrossRef]

19. Solsona, B.; García, A.M.D.; Aylón, E.; Dejoz, A.M.; Vázquez, I.; Agouram, S.; Davies, T.E.; Taylor, S.H. Promoting the activity and selectivity of high surface area $\mathrm{Ni}-\mathrm{Ce}-\mathrm{O}$ mixed oxides by gold deposition for VOC catalytic combustion. Chem. Eng. J. 2011, 175, 271-278. [CrossRef]

20. Zhang, X.; Wang, H.; Xu, B.-Q. Remarkable Nanosize Effect of Zirconia in Au/ZrO2Catalyst for CO Oxidationt. J. Phys. Chem. B 2005, 109, 9678-9683. [CrossRef]

21. Campa, M.; Ferraris, G.; Gazzoli, D.; Pettiti, I.; Pietrogiacomi, D. Rhodium supported on tetragonal or monoclinic $\mathrm{ZrO} 2$ as catalyst for the partial oxidation of methane. Appl. Catal. B Environ. 2013, 142, 423-431. [CrossRef]

22. Matsui, K.; Ohgai, M. Formation Mechanism of Hydrous Zirconia Particles Produced by the Hydrolysis of ZrOCl2 Solutions: III, Kinetics Study for the Nucleation and Crystal-Growth Processes of Primary Particles. J. Am. Ceram. Soc. 2004, 84, 2303-2312. [CrossRef]

23. Aparicio, M.L.; Ocsachoque, M.A.; Gazzoli, D.; Botto, I.L.; Lick, I.D. Total Oxidation of Naphthalene with Zirconia-Supported Cobalt, Copper and Nickel Catalysts. Catalysts 2017, 7, 293. [CrossRef]

24. Montaña, M.; Aparicio, M.L.; Ocsachoque, M.A.; Navas, M.B.; Barros, I.; Rodríguez-Castellón, E.; Casella, M.L.; Lick, I.D. Zirconia-Supported Silver Nanoparticles for the Catalytic Combustion of Pollutants Originating from Mobile Sources. Catalysts 2019, 9, 297. [CrossRef]

25. Rhodes, M.D.; Bell, A.T. The effects of zirconia morphology on methanol synthesis from CO and H2 over $\mathrm{Cu} / \mathrm{ZrO} 2$ catalysts: Part I. Steady-state studies. J. Catal. 2005, 233, 198-209. [CrossRef]

26. Benito, M.; Padilla, R.M.; Rodríguez, L.; Sanz, J.; Daza, L. Zirconia supported catalysts for bioethanol steam reforming: Effect of active phase and zirconia structure. J. Power Sources 2007, 169, 167-176. [CrossRef]

27. Toraya, H.; Yoshimura, M.; Somiya, S. Calibration Curve for Quantitative Analysis of the Monoclinic-Tetragonal ZrO2System by X-Ray Diffraction. J. Am. Ceram. Soc. 1984, 67, 119-121. [CrossRef]

28. Jaworski, M.; Lick, I.D.; Siri, G.J.; Casella, M.L. ZrO2-modified Al2O3-supported PdCu catalysts for the water denitrification reaction. Appl. Catal. B Environ. 2014, 156, 53-61. [CrossRef]

29. Wyrwalski, F.; Lamonier, J.-F.; Siffert, S.; Aboukaïs, A. Additional effects of cobalt precursor and zirconia support modifications for the design of efficient VOC oxidation catalysts. Appl. Catal. B Environ. 2007, 70, 393-399. [CrossRef] 
30. Labaki, M.; Siffert, S.; Lamonier, J.-F.; Zhilinskaya, E.A.; Aboukaïs, A. Total oxidation of propene and toluene in the presence of zirconia doped by copper and yttrium. Appl. Catal. B Environ. 2003, 43, 261-271. [CrossRef]

31. Fierro, G. A Study of Anomalous Temperature-Programmed Reduction Profiles of $\mathrm{Cu} 2 \mathrm{O}, \mathrm{CuO}$, and $\mathrm{CuO}-\mathrm{ZnO}$ Catalysts. J. Catal. 1994, 148, 709-721. [CrossRef]

32. Solsona, B.; Aylón, E.; Murillo, R.; Mastral, A.M.; Monzonís, A.; Agouram, S.; Davies, T.E.; Taylor, S.H.; García, A.M.D. Deep oxidation of pollutants using gold deposited on a high surface area cobalt oxide prepared by a nanocasting route. J. Hazard. Mater. 2011, 187, 544-552. [CrossRef] [PubMed]

33. Centi, G.; Cerrato, G.; D'Angelo, S.; Finardi, U.; Giamello, E.; Morterra, C.; Perathoner, S. Catalytic behavior and nature of active sites in copper-on-zirconia catalysts for the decomposition of N2O. Catal. Today 1996, 27, 265-270. [CrossRef]

34. Liu, S.Y.; Yang, S.M. Complete oxidation of 2-propanol over gold-based catalysts supported on metal oxides. Appl. Catal. A Gen. 2008, 334, 92-99. [CrossRef]

35. Chen, Y.-H.; Mou, C.-Y.; Wan, B.-Z. Ultrasmall gold nanoparticles confined in zeolite Y: Preparation and activity in CO oxidation. Appl. Catal. B Environ. 2017, 218, 506-514. [CrossRef]

36. Grzona, C.B.; Lick, I.D.; Rodríguez-Castellón, E.; Ponzi, M.I.; Ponzi, E.N. Cobalt and KNO3 supported on alumina catalysts for diesel soot combustion. Mater. Chem. Phys. 2010, 123, 557-562. [CrossRef]

37. Yao, J.; Lu, H.; Xiao, Y.; Hou, B.; Li, D.; Jia, L. Sub-molten salt-acid treatment of LaCoO3 for a highly active catalyst towards propane combustion. Catal. Commun. 2019, 128, 105718. [CrossRef]

38. Liotta, L.F.; Di Carlo, G.; Pantaleo, G.; Venezia, A.M.; Deganello, G. Co3O4/CeO2 composite oxides for methane emissions abatement: relationship between $\mathrm{Co}_{3} \mathrm{O}_{4}-\mathrm{CeO}_{2}$ interaction and catalytic activity. Appl. Catal. B Environ. 2006, 66, 217-227. [CrossRef]

39. Wang, H.-T.; Liu, Y.-N.; Kang, X.-H.; Wang, Y.-F.; Yang, S.-Y.; Bian, S.-W.; Zhu, Q. Flexible hybrid yarn-shaped supercapacitors based on porous nickel cobalt sulfide nanosheet array layers on gold metalized cotton yarns. J. Colloid Interface Sci. 2018, 532, 527-535. [CrossRef]

40. Solsona, B.; García, T.; Agouram, S.; Hutchings, G.J.; Taylor, S.H. The effect of gold addition on the catalytic performance of copper manganese oxide catalysts for the total oxidation of propane. Appl. Catal. B Environ. 2011, 101, 388-396. [CrossRef]

41. Solsona, B.; Pérez-Cabero, M.; Vázquez, I.; Dejoz, A.; García, T.; Alvarez-Rodriguez, J.; El-Haskouri, J.; Beltrán, D.; Amorós, P.; García, A.M.D. Total oxidation of VOCs on Au nanoparticles anchored on Co doped mesoporous UVM-7 silica. Chem. Eng. J. 2012, 187, 391-400. [CrossRef]

42. Li, X.; Li, X.; Zeng, X.; Zhu, T. Correlation between the physicochemical properties and catalytic performances of micro/mesoporous CoCeO mixed oxides for propane combustion. Appl. Catal. A Gen. 2019, 572, 61-70. [CrossRef]

43. Solsona, B.; Sanchis, R.; Dejoz, A.M.; García, A.M.D.; Ruiz-Rodríguez, L.; Nieto, J.M.L.; Cecilia, J.A.; Rodríguez-Castellón, E. Total Oxidation of Propane Using CeO2 and CuO-CeO2 Catalysts Prepared Using Templates of Different Nature. Catalysts 2017, 7, 96. [CrossRef]

44. García, A.M.D.; Sellick, D.; Varela, F.; Vázquez, I.; Dejoz, A.; Agouram, S.; Taylor, S.H.; Solsona, B. Total oxidation of naphthalene using bulk manganese oxide catalysts. Appl. Catal. A Gen. 2013, 450, 169-177. [CrossRef]

45. Wu, H.; Wang, L.; Zhang, J.; Shen, Z.; Zhao, J. Catalytic oxidation of benzene, toluene and p-xylene over colloidal gold supported on zinc oxide catalyst. Catal. Commun. 2011, 12, 859-865. [CrossRef]

(C) 2020 by the authors. Licensee MDPI, Basel, Switzerland. This article is an open access article distributed under the terms and conditions of the Creative Commons Attribution (CC BY) license (http://creativecommons.org/licenses/by/4.0/). 